\title{
PERCEPÇĀO DOS ENFERMEIROS SOBRE AS ATIVIDADES QUE DESENVOLVEM EM SUAS UNIDADES DE TRABALHO
}

\author{
Paulina Kurcgant** \\ Maria Cristina K. Braga Massarallo**** \\ Valéria Castilho** \\ Vanda Elisa Felli da Silua**
}

KURCGANT, P. et al. Percepgáo dos enfermeiros sobre as atividades que desenvolvem em suas unidades de trabalho. Rev. Esc. Enf. USP., v. 27, n. 2, p. 229-45, ago. 1993.

$O$ presente estudo objetiva o conhecimento das atividades realizadas pelas enfermeiras de unidades de internaçāo e ambulatório de um hospital de ensino e conhecer como percebem o desenvolvimento dessas atividades. Como populaçáo do estudo, foram consideradas 19 enfermeiras lotadas em diferentes unidades do hospital. Para a obtençáo dos dados foi adotada a técnica de entrevista estruturada. As informaçós obtidas foram analisadas nos seus aspectos quantitativos e qualitativos. Constatou-se que as enfermeiras desenvolvem suas atividades profissionais de forma rotineira, embasadas na tradiçào e na autoridade e nào na reflexáo sobre a prática.

UNITERMOS: Exercicio da enfermagem. Serviços de Enfermagem.

\section{INTRODUÇĀO}

Está implícito, aos individuos que exercem uma profissāo, o desempenho de um papel profissional. Esse papel é entendido como o conjunto de comportamentos esperados de todos ao ocuparem determinados cargos na organização, independentemente, de quem seja a pessoa ${ }^{10}$, compreendendo, portanto, um conjunto de padrōes culturais. Esse conjunto, por sua vez, se relaciona a atitudes, valores e comportamentos que a sociedade atribui às pessoas que ocupam posiçōes específicas e que, em função disso, alimentam expectativas legítimas em relação ao comportamento dessas pessoas ${ }^{10}$.

Enfermeira. Professor Doutor do Departamento de Orientaçăo Profissional da Escola de Enfermagem da Unıversıdade de Sào Paulo - Disciplına Adminıstraçáo aplicada a Enfermagem. COREN SP 013

- Enfermeira. Assistente do Departamento de Orientaçáo Profissional da Escola de Enfermagem da Univeràdade de Sảo Paulo - Disciplına Administraçảo aplıcada a Enfermagem. COREN.SP I7375. 18451 e 13666 
O papel profissional desempenhado pelos enfermeiros nas organizaçōes, está relacionado ao desenvolvimento de atividades específicas que caracterizam a profissão.

Essas atividades, entendidas como um conjunto de açōes orientadas para a realizaçāo de um objetivo ${ }^{3}$, devem referendar o produto de um conjunto de crenças e valores próprios do grupo ao qual pertencem, ou seja, de uma filosofia ${ }^{6}$.

A filosofia é operacionalizada pelo estabelecimento de objetivos que permite converter as convicçóes em açōes. Assim, ela norteia todas as ações de enfermagem, não só explicitando seus fundamentos mas, ta mbém, conferindo-lhes um significado. Desse modo, os enfermeiros podem realizar as atividades de modo consciente e coerente.

Muitas vezes, a dificuldade na definiçāo do "fazer" pelos diferentes elementos da equipe de enfermagem é decorrente da falta de uma filosofia que contemple todas as conviç̧ōes desse grupo ou do fato desta filosofia não estar explícita, proporcionando, assim, uma condição para que cada elemento atue conforme suas próprias convicçóes.

Nesse sentido, CASTELLANOS; CASTILHO ${ }^{5}$ referem que sem uma filosofia de enfermagem que dê bases para o seu desenvolvimento, torna-se impossível determinar a área de responsabilidade profissional, sendo que cada enfermeiro poderá interpretar diferentemente a profissâo e, conseqüentemente, as atividades de enfermagem.

Segundo essas autoras ${ }^{5}$, é a filosofia de enfermagem que direciona as açōes de planejamento, orientaçāo, avaliaçāo e controle de condutas, bem como a definição e aplicação de princípios de decisão. Assim, quando nāo existe uma filosofia norteadora das ações, as atividades relativas aos processos de planejamento e decisão ficam prejudicadas pela dificuldade no estabelecimento de prioridades em relação às atividades a serem realizadas.

A definiçāo das atividades de enfermagem para os elementos que compōem esta equipe tem sido discutida considerando diferentes enfoques, entre eles, o teórico, o legal e o histórico.

No enfoque teórico, as atividades de enfermagem a serem realizadas com a finalidade de assistir à clientela, são consideradas nos seus diferentes graus de complexidade e no preparo requerido para a execuçāo.

Esses diferentes graus de complexidade podem ser concebidos num esquema contínuo e crescente, visualizado na Figura $1^{11}$. Esse esquema explicita três grupos de atividades e alia a capacitação dos elementos da equipe ao grau de complexidade das atividades a serem realizadas. Explicita, também, que enquanto para alguns elementos da equipe as atividades a serem realizadas são limitadas, para a enfermeira isso nāo ocorre. Assim, a ela compete as funçōes mais complexas que exigem pericia e capacidade de julgamento, assumindo, no entanto, a responsabilidade pelo desenvolvimento das ativida- 
des pelos outros elementos da equipe. Além disso, a extremidade aberta do esquema simboliza um campo ilimitado de atuação do enfermeiro e a autonomia para assumir outras atividades.

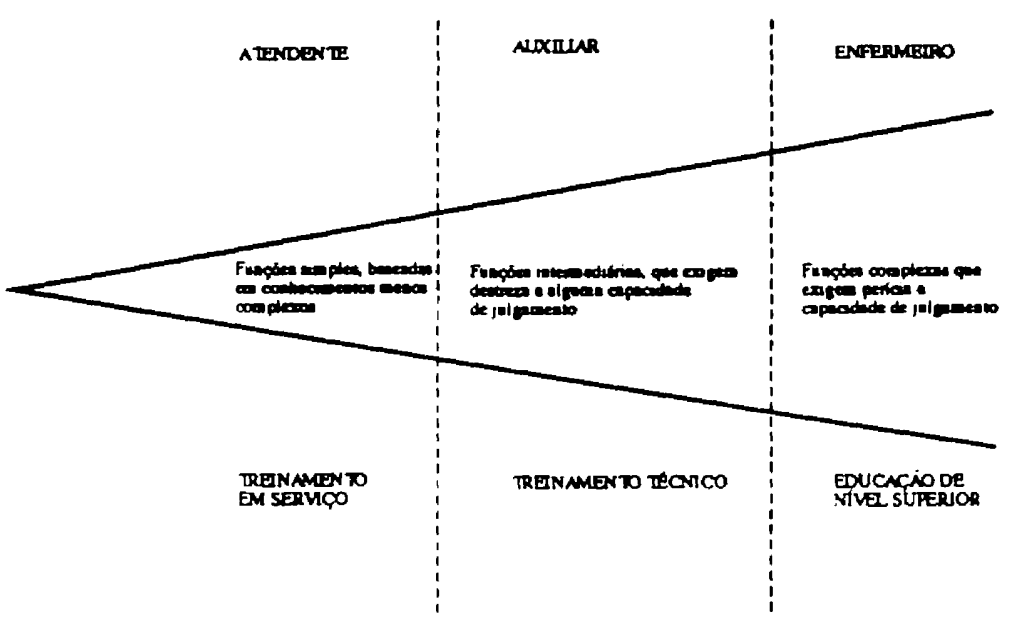

Segundo um enfoque legal, o critério de complexidade e preparo também sảo considerados para a definiçáo de atividades. A Lei do Exercício Profissional ${ }^{1}$ e a sua Regulamentaçāo ${ }^{2}$, estabelecem as atividades que competem aos diferentes elementos da equipe de enfermagem cabendo, ao enfermeiro, o exercício de todas as atividades de enfermagem e, privativamente, aquelas relacionadas na Lei.

No entanto, para a aplicação dessa $\operatorname{Lei}{ }^{1}$, há necessidade do estabelecimento de critérios de complexidade específicos para cada Serviço, o que se constitui em uma tarefa difícil se nāo ocorrer uma reflexāo profunda sobre a prática específica de cada grupo de enfermagem e, assim, tornar viável a delimitação de atividades, segundo esse critério.

A análise da historicidade do trabalho de enfermagem permite verificar que existe na prática de seu exercício, um parcelamento do trabalho, cabendo à enfermeira a detenção do saber e a função intelectual de gerenciamento e, ao pessoal auxiliar, o serviço manual que. segundo MELO ${ }^{12}$, é depreciado. Esse processo que caracteriza a divisão social e técnica do trabalho de enfermagem, dificulta a sua visualização global. Com isso há um impedimento na participaçáo de todos os elementos da equipe no processo de planejamento, execuçāo e avaliação do trabalho realizado, dificultando, assim, a união desse grupo em torno de objetivos comuns. 
Nesse processo, a enfermeira assume a função de gerente, identificando-se com os interesses institucionais e distanciando-se das atividades condizentes com o seu preparo técnico específico, voltados para a assistência aos pacientes ${ }^{12}$.

A falta de uma filosofia de enfermagem e a divisão social e técnica do trabalho têm provocado conflitos em relação ao objeto de trabalho do enfermeiro, gerando discussoes sobre o resgate da execução da assistência ao paciente ou da continuidade das atividades de gerenciamento.

Esses conflitos têm conduzido a uma série de dificuldades e questionamentos em relação à formação profissional, ao exercício profissional e à definiçāo de papéis dentro da equipe de enfermagem e da equipe multiprofissional.

Ainda, o processo da divisão de trabalho e o seu parcelamento têm limitado o desenvolvimento de conhecimentos e habilidades sobre o objeto de trabalho, dificultando o crescimento da enfermagem como profissăo.

Autores como KAST; ROSENZWEIG ${ }^{10}$ referem que é no desempenho do papel profissional que o trabalho é reconhecido porque envolve o desenvolvimento de conhecimentos, de habilidades, de autonomia, de compromisso e de responsabilidade das pessoas que o praticam. CAPELla et al ${ }^{4}$ reforçam essa idéia referindo que é através do desempenho do papel que se dá o processo de profissionalizaçāo, que inclui, não somente a formaçāo técnica, mas, também, a prática organizada e garantida com maior ou menor força de lei.

Apesar de todos os conflitos e dificuldades vivenciados no seu "fazer", os enfermeiros têm procurado avançar rumo à profissionalizaçāo.

Assim, a pesquisa sobre as atividades que o enfermeiro realiza no seu cotidiano de trabalho e o significado que confere a essas atividades são importantes quando possibilitam a compreensão de como os enfermeiros estão inseridos nesse processo de profissionalizaçăo e justificam a realização desse estudo.

\section{OBJETIVOS DO ESTUDO}

- Verificar as atividades desenvolvidas pelas enfermeiras em unidades de internaçáo e de ambula tório do hospital campo de estudo.

- Conhecer como as enfermeiras percebem as atividades por elas desenvolvidas nas suas unidades de trabalho.

- subsidiar a reflexảo sobre a prática de enfermagem. 


\section{METODOLOGIA}

O estudo foi realizado em um hospital geral, de ensino, do município de São Paulo.

O motivo da escolha deu-se pelo fato do mesmo ser campo de prática dos estudantes de graduaçāo em enfermagem, da Escola de Enfermagem da Universidade de São Paulo, no estágio da disciplina Administraçäo aplicada à Enfermagem.

Como população do estudo, foram consideradas 19 enfermeiras, estando, lotadas nas diferentes unidades de internação e ambulatório do hospital, onde estava sendo realizado o estágio dos alunos.

Para a obtenção dos dados foi adotada a técnica da entrevista estruturada, conforme instrumento em anexo. As entrevistas foram realizadas pelos alunos, nas diferentes unidades em que estavam estagiando.

As informaçóes obtidas foram analisadas nos seus aspectos quantitativos e qualitativos. Com a análise quantitativa procurou-se a verificação numérica e a freqüência das atividades desenvolvidas pelas enfermeiras populaçāo do estudo e com a análise qualitativa o resgate da percepçáo, pelas justificativas das enfermeiras, da realiza ção dessas atividades.

\section{APRESENTAÇÃO E ANÁLISE DOS RESULTADOS}

Para apresentaçāo dos dados foram elaboradas tabelas demonstrativas das atividades desenvolvidas pelas enfermeiras. Essas atividades foram relacionadas com as justificativas apresentadas e codificadas para facilidade de compreensão dos dados.

As atividades referidas pelas enfermeiras foram classificadas em grupos temáticos, sem limitaçōes de ordem teórica. Ressalta-se, assim, o fato das atividades terem sido aceitas sem restriçōes conceituais.

Dessa forma, como dados coletados, foram aceitas, sob a denominação de "atividade", funçōes e processos administrativos.

Assim, para a análise dos dados obtidos nas entrevistas, as atividades desenvolvidas pelas enfermeiras foram reunidas em 6 grupos: atividades relacionadas à assistência direta aos pacientes (tabela 1); à administração do pessoal de enfermagem (tabela 2); à administração de recursos materiais (tabela 3 ); ao sistema de informação adotado (tabela 4); à burocracia constituída (tabela 5) e, como sexto grupo, às atividades não classificadas nos grupos anteriores (tabela 6). 
Conforme a sistemática adotada, serāo apresentados os dados referentes a cada grupo de atividades.

\subsection{ATIVIDADES DESENVOLVIDAS PELAS ENFERMEIRAS, RELA- CIONADAS A ASSISTẾNCLA DIRETA AOS PACIENTES}

Como demonstra a tabela 1 , as atividades selecionadas à assistência direta aos pacientes foram referidas, pelo menos uma vez, por todas as enfermeiras que fizeram parte do estudo, perfazendo um total de 54 citaçōes. Assim, baseando-se nesse dado e comparando-o com os dados das tabelas seguintes, verifica-se que essas atividades são as que as enfermeiras mais referem desenvolver nas suas unidades de trabalho.

TABELA 1 - DISTRIBUIÇĀO DAS ATIVIDADES DESENVOLVIDAS PELAS ENFERMEIRAS JUNTO AOS PACIENTES, COM AS RESPECTIVAS JUSTIFICATIVAS. SÄO PAULO, 1991.

\begin{tabular}{|c|c|c|c|c|c|c|c|c|c|c|c|c|c|c|c|c|c|c|c|c|}
\hline Alideden & 1 & 2 & 3 & 4 & 5 & 6 & 7 & - & $\theta$ & 101 & 11 & 12 & 1361 & & 15 & 10 & 17 & \begin{tabular}{l|l|l|}
18 & 18
\end{tabular} & $\begin{array}{l}n \\
d e \\
\text { Emt }\end{array}$ & $\begin{array}{l}x \\
n=19\end{array}$ \\
\hline 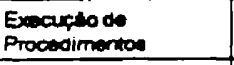 & & $\mathrm{FGH}$ & $E$ & & & $E$ & E & $J$ & $L$ & & & $c$ & A & & & $k$ & $E$ & $c \mid E$ & 12 & 63,16 \\
\hline Oriertepto & A & $\theta$ & $E$ & & & $\mathbf{B}$ & $E$ & & & & A & c & \begin{tabular}{l|l}
$A$ & $L$ \\
\end{tabular} & $\mathrm{LM}$ & $E$ & $M$ & & 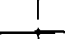 & 11 & 57.89 \\
\hline $\begin{array}{l}\text { Prontacios de } \\
\text { Cuidedoes }\end{array}$ & $\bar{A}$ & $\sqrt{1}$ & $F$ & & $A$ & & $E$ & FJK & & & & c & & $K N$ & & & & $E$ & 9 & 47.37 \\
\hline Evolucto & $A$ & & $E$ & A & & & $E$ & $E$ & & & & & & c & KO & $E$ & 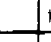 & $x$ & 9 & 47.37 \\
\hline Prowencio & & & $E$ & $E$ & & & E & & & $E$ & & & & & & & c & & $E$ & \\
\hline 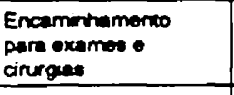 & A & & & $A$ & & & $E$ & $E$ & & & & & & & & $E$ & & & 5 & 26.31 \\
\hline $\begin{array}{l}\text { Conaultu de } \\
\text { ontermingern }\end{array}$ & & & & & & & 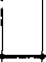 & & & & & & A & & & & & & & 1 \\
\hline 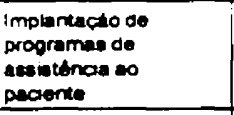 & & & & & & & & & & $E$ & & & & & & & & & 1 & 5.26 \\
\hline TOTAL & & & & & 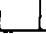 & & & & & & & & & & & & & 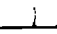 & & \\
\hline
\end{tabular}

Legenda:

A - Importante porque beneficia o paciente.

B - Importante para o paciente ter conhecimento sobre o tratamento.

C - Importante.

D - Importante para o paciente conhecer a dinâmica da unidade.

E - Não tem justificativa.

F - Enfermeiro é o elemento mais preparado da equipe de enfermagem.

G - Diminui a infecção.

H - Para dar apoio psicológico.

I - É funçào da enfermagem.

$J$ - Porque há falta de funcionários. 
K - Para avaliar o paciente.

L - Para saber priorizar as atividades para os pacientes.

M - Diminuir a ansiedade dos pacientes.

N - Para prescrever cuidados.

O - Para dar continuidade aos pacientes.

Nesse grupo de atividades relacionadas à assistência direta ao paciente, as atividades referentes à execução de procedimentos, tais como, controle de sinais vitais, sondagens e curativos, foram as mais citadas, sendo mencionadas por $12(63,16 \%)$ das 19 enfermeiras. Dessas 12 enfermeiras, a metade năo atribuiu importância à realização dessas atividades. Três enfermeiras consideraram-nas apenas "importantes". As outras justificativas citadas pelos enfermeiros no desenvolvimento dessas atividades, nāo estavam relacionadas ao preparo técnico específico necessário e à complexidade que envolve a realizaçāo de um procedimento, näo sendo percebido, por elas, como critérios para delimitar a execução de procedimentos entre os elementos da equipe.

Conforme a Lei do Exercício Profissional de Enfermagem ${ }^{1}$, a execução de procedimentos não é prerrogativa dos enfermeiros, podendo ser realizada por outros elementos da equipe de enfermagem. Ao enfermeiro cabe, privativamente, "os cuidados diretos de enfermagem a pacientes graves com risco de vida" $e$ "cuidados de enfermagem de maior complexidade técnica e que exijam conhecimentos de base científica e capacidade de tomar decisōes imediatas".

Ainda, dentre as atividades relacionadas à assistência direta ao paciente, encontram-se as referentes à "prestação de cuidados" e foram agrupadas, no estudo, como "cuidados". Assim, nas falas das enfermeiras os "cuidados" integram diferentes açōes que são executadas no atendimento aos pacientes, em diferentes condiçōes, como "cuidados a pacientes em parada cárdio-respiratória", "cuidados a pacientes graves", "cuidados a pacientes de UTI" e "cuidados a pacientes em pós-operatório imediato". Entretanto, nāo são explicitadas pelas enfermeiras, as açōes que, segundo elas, constituem esses "cuidados". Essa atividade foi mencionada por $9(47,37 \%)$ das 19 (100\%) enfermeiras.

Ainda quanto à prestação de cuidados aos pacientes há divergèncias entre as enfermeiras no que se refere à importância que atribuem a essas atividades. Por um lado, justificam a realizaçāo das atividades por acreditarem ser funçāo da enfermeira e por considerarem a enfermeira o elemento mais preparado da equipe. Por outro lado, realizam a tarefa devido a "falta de funcionários".

Segundo a Legislaçāo vigente ${ }^{1.2}$, algumas atividades, como consulta, prescrição e evoluçăo de enfermagem, sảo privativas do enfer- 
meiro. Apesar dessas atividades serem exclusivas desse profissional, ao contrário de outras que podem ser realizadas por outros elementos da equipe de enfermagem, foram pouco mencionadas se comparadas às atividades citadas anteriormente. Chama atençāo o fato de que, apesar de serem atividades específicas do enfermeiro, obtiveram o menor índice de justificativas para a sua realizaçāo.

\subsection{ATIVIDADES RELACIONADAS A ADMINISTRAÇÃO DO PES- SOAL DE ENFERMAGEM}

$\mathrm{Na}$ tabela 2 verifica-se que as atividades classificadas nesse grupo totalizam 43 citaçōes, resgatadas nas falas de 14 enfermeiras.

TABELA 2 - DISTRIBUIÇÃO DAS ATIVIDADES DESENVOLVIDAS PELAS ENFERMEIRAS JUNTO À EQUIPE DE ENFERMAGEM, COM AS RESPECTIVAS JUSTIFICATIVAS. SẢO PAULO, 1991.

\begin{tabular}{|c|c|c|c|c|c|c|c|c|c|c|c|c|c|c|c|c|c|c|c|c|c|}
\hline Auvideden & 1 & 2 & 3 & 4 & 5 & 6 & 7 & 8 & 9 & 10 & 111 & 121 & 13 & 14 & 15 & 18 & 17 & 18 & $19\left[\begin{array}{l}n \\
d e \\
\text { Er }\end{array}\right.$ & $\begin{array}{l}\infty \\
\text { de } \\
\text { Ent }\end{array}$ & $\sum_{n=18}^{\infty}$ \\
\hline $\begin{array}{l}\text { Supormadal } \\
\text { Obaervecto }\end{array}$ & A & & 10 & c & & & c & 0 & & c & & & & 6 & s & A & $N$ & 8 & \begin{tabular}{l|l}
0 & 12 \\
$P$ & \\
\end{tabular} & 12 & 63.10 \\
\hline 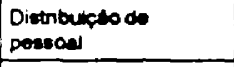 & A & & 0 & & & & c & c & & lc & & & & $k$ & & 0 & $\mathrm{~N}$ & & $P \mid 9$ & 9 & 47.37 \\
\hline 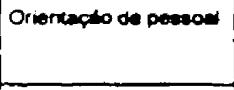 & A & & $c$ & & & & c & & & & E & & A & & L & $M$ & & & \begin{tabular}{l|l}
$A$ & 8 \\
0 & \\
& \\
\end{tabular} & 8 & 42.101 \\
\hline $\begin{array}{l}\text { Treunumento de } \\
\text { Deasoal }\end{array}$ & & & & & & & & & & c & $H$ & & 1 & 1 & & f & & & & 4 & 21.05 \\
\hline $\begin{array}{l}\text { Avaliecilo de } \\
\text { desomperno }\end{array}$ & & & & & & & C & & & & & & 」 & \lrcorner & & & & & s $\mid 3$ & 3 & $|15.78|$ \\
\hline Control de treqüencia & & & & & & & & & & $c$ & & & & & & & & & $c \mid 2$ & 2 & $: 2.43$ \\
\hline 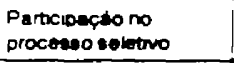 & & & & & & & & c & & & & & & & & & & 1 & & & 5.26 \\
\hline $\begin{array}{l}\text { Coord oneptio do } \\
\text { trabalno em equpe }\end{array}$ & & & & & & & & & & & 1 & & & & & & & & 1 & 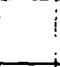 & 5.28 \\
\hline L Wderanca & & & & & & & & & & & $G$ & & & & & & & & 1 & & 5.26 \\
\hline Reurndes & & & & & & $c$ & & & $\vdots$ & & $!$ & 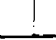 & & & & $i$ & & 1 & 1 & & 526 \\
\hline
\end{tabular}

Legenda:

A - Importante porque beneficia o paciente.

B - Importante.

C - Não justificou.

D - Para saber de quem cobrar a tarefa realizada.

E - Melhora a coordenaçáo do serviço.

F - É a base do bom andamento da clínica.

G - Para ter respaldo médico.

$\mathrm{H}$ - Para manter o funcionário orientado sobre as rotinas. 
I - Para estruturar bem o serviço para a realizaçāo das atividades.

$\mathrm{J}$ - Pessoal mais qualificado para atender o paciente.

$\mathrm{K}$ - Para garantir número suficiente de funcionário para dar uma assistência de boa qualidade.

L - Para mudar a "cabeça" do pessoal.

M - Porque existem muitos problemas referentes à execuçảo de procedimentos.

N - Se a enfermeira nāo fizer, os funcionários ficam perdidos.

O - Para avaliar o desempenho do funcionário.

P - Para evitar atrito entre os funcionários.

Q - Para aumentar o desempenho do funcionário.

$R$ - Porque valoriza o cargo da enfermeira.

S - Para saber como os funcionários estảo fazendo suas atividades.

Dentre essas atividades mencionadas, a que recebeu maior número de citaçōes foi a que se refere à Supervisāo/Observação. Dessa forma, $12(63,16 \%)$ das $19(100 \%)$ enfermeiras referiram realizar essa “atividade". Depreende-se, também, que para essas enfermeiras o termo "supervisāo" tem o mesmo significado de "observaçāo", considerando supervisão como atividade e não como funçäo.

Para essas enfermeiras, ainda, a supervisăo é exercida com a finalidade de controle de pessoal, uma vez que as atividades de orientação foram citadas como um item em separado. Assim, as enfermeiras näo percebem a orientação do pessoal como uma atividade integrante da funçāo supervisāo. Segundo o Ministério da Saúde ${ }^{3}$, supervisão é um processo educativo e contínuo, que consiste fundamentalmente em motivar e orientar os supervisionados na execuçāo de atividades, a fim de manter elevada a qualidade dos serviços. Segundo essa concepção, "a supervisāo vem sendo caracterizada como uma função administrativa que envolve um processo de orientação contínua de pessoal, com a finalidade de desenvolvê-lo e capacitá-lo para o serviço"?.

Cabe ressaltar que essa atividade denominada "supervisāo" apresentou baixo índice de justificativas, sugerindo que as enfermeiras nāo têm claro o motivo pelo qual a realizam.

Uma citação que chama a atenção é a de uma enfermeira que referiu exercer a atividade de "liderança". Além de considerar o papel de líder como uma atividade, justifica a sua importância com a finalidade de manter um bom relacionamento com a equipe médica, não fazendo menção à equipe de enfermagem. Nesse caso, a liderança é percebida de forma equivocada segundo a literatura, uma vez que, para HERSEY:BLANCHARD ${ }^{9}$ liderança é o processo de exercer influência sobre um indivíduo ou grupo, nos esforços para a realizaçāo de objetivos em determinada situação. 


\subsection{ATIVIDADES DESENVOLVIDAS PELAS ENFERMEIRAS, RELA- CIONADAS A ADMINISTRAÇĀO DE RECURSOS MATERIAIS}

Conforme demonstra a tabela 3 , atividades relacionadas à administraçāo de recursos materiais foram citadas 22 vezes, na fala de 12 enfermeiras.

TABELA 3 - DISTRIBUIÇÃO DAS ATIVIDADES DESENVOLVIDAS; PELAS ENFERMEIRAS PARA ADMINISTRAÇĀO DOS RECURSOS MATERIAIS COM AS RESPECTIVAS JUSTIFICATIVAS. SÃO PAULO, 1991.

\begin{tabular}{|c|c|c|c|c|c|c|c|c|c|c|c|c|c|c|c|c|c|c|c|c|c|}
\hline Abvidedes & 1 & 2 & 3 & 4 & 5 & $\theta$ & 7 & 6 & 10 & 10 & 11 & & 13 & 14 & 15 & 16 & 17 & 18 & 18 & $\begin{array}{l}n \\
\text { de } \\
\text { Ent. }\end{array}$ & $\begin{array}{l}\infty \\
n=19 \\
\end{array}$ \\
\hline 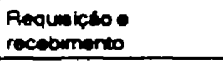 & & & & & & $F$ & $\mathrm{C}$ & & c & & & & & $G$ & & $c$ & c & & 1 & 7 & 36.84 \\
\hline $\begin{array}{l}\text { Controlo do } \\
\text { medicarmentoes de } \\
\text { emergincie }\end{array}$ & $A$ & & C & $A$ & & & & & & & & & & $G$ & $\mathrm{H}$ & $H$ & C & & & 7 & 36,84 \\
\hline Promedo & $A$ & & & & & $F$ & $c$ & & c & & & & & & & & & & & 4 & 29.05 \\
\hline Mariminciodo de & & & c & & & & & & & & & & & & & & & & 1 & 2 & 10.53 \\
\hline Manuceso do & & & DE & & & & & & & & & & & & & & & & & 1 & 5,28 \\
\hline $\begin{array}{l}\text { Improviacesto os } \\
\text { matenal }\end{array}$ & & & & & & & & & & & & 8 & & & & & & & & 1 & 5.28 \\
\hline
\end{tabular}

\section{Legenda:}

A - Importante porque beneficia o paciente.

B - Importante.

c - Não justificou.

D - Para ter eficiència numa parada cárdio-respiratória.

E - Há um enriquecimento profissional.

F - Porque nảo dá para trabalhar sem material.

G - Para proporcionar condiçoes materia is para o tratamento do paciente.

H - Para dar segurança ao paciente.

I - Porque é necessário a assinatura da enfermeira.

Nesse grupo de atividades, o controle a parece apenas em relação à medicamentos de emergência, tendo como justificativa a preocupação com o bem estar e com a segurança do paciente em situações criticas.

As atividades relativas à administraçāo de material, tais como requisiçāo, recebimento e controle de materiais receberam maior número de citações, em detrimento da atividade de previsão de material que requer, para sua análise, conhecimentos referentes à clientela, aos recursos humanos e às características da unidade. Assim sendo, seria de se esperar que a atividade de previsảo de material 
deveria receber mais atenção por parte da enfermeira interessada em assistir o paciente em suas necessidades.

Em relação à requisiçāo e recebimento de material, uma enfermeira justificou essa atividade referindo que a faz "por que é necessária a assinatura da enfermeira", denotando com isso a realizaçáo dessa atividade, unicamente como cumprimento a uma exigência da instituiçāo e nāo por perceber a importância da mesma na sua prática profissional.

\subsection{ATIVIDADES DESENVOLVIDAS PELAS ENFERMEIRAS RELA- CIONADAS AO SISTEMA DE INFORMAÇÄO ADOTADO}

Como podemos verificar na tabela 4, as atividades relacionadas ao sistema de informaçăo, emergiram da fala de 8 enfermeiras, recebendo 13 citaçōes.

TABELA 4 - DISTRIBUIÇĀO DAS ATIVIDADES DESENVOLVIDAS PELAS ENFERMEIRAS REFERENTES AO SISTEMA DE INFORMAÇĀO," COM AS RESPECTIVAS JUSTIFICATIVAS. SĀO PAULO, 1991.

\begin{tabular}{|c|c|c|c|c|c|c|c|c|c|c|c|c|c|c|c|c|c|c|c|c|c|}
\hline Atvidedeo & 1 & 2 & 3 & 4 & 5 & 6 & 7 & 18 & 9 & 10 & 11 & 12 & 13 & 14 & 15 & 10 & 17 & 18 & 18 & $\begin{array}{l}\infty \\
\infty \\
\text { Ent }\end{array}$ & $\begin{array}{l}x \\
n=19\end{array}$ \\
\hline 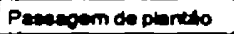 & A & & C & & & & $B$ & & & & & & & & & $B$ & & & $\theta$ & 5 & 28,31 \\
\hline $\begin{array}{l}\text { Communcacto of } \\
\text { ooorrinase }\end{array}$ & & & 0 & & & & 8 & & & & & & A & & & & & & & 3 & 15.79 \\
\hline 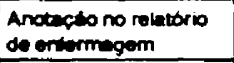 & & & & & & & & & & & & & & & & $F$ & A & & & 2 & 10.53 \\
\hline $\begin{array}{l}\text { Anctuction no } \\
\text { promulio do pacierte }\end{array}$ & & & 8 & & & & & & & & & & & & & & & & & i & 5.28 \\
\hline $\begin{array}{l}\text { Acompontramente das } \\
\text { viecta meorice }\end{array}$ & & & & & & & & & & & & & & & & & & & $G$ & T. & 15.26 \\
\hline Elaboracto de sotinas & & & & & & & & & i & & & i & i & $E$ & & & i & $i$ & & 1 & 5.26 \\
\hline
\end{tabular}

Legenda:

A - Importante porque beneficia o paciente.

B - Não justificou.

C - Possibilita a continuidade da assistência.

D - Favorece o conhecimento profissional.

E - Especifica quem vai fazer a atividade.

$F$ - Favorece a troca de informaçóes entre os plantóes.

G - Para atender a equipe médica, para ter um bom relacionamento com ela.

Nesse grupo, uma das atividades referidas foi a passagem de plantäo. Sabe-se que essa atividade é realizada em todas as unidades, nas quais os alunos estagiam mas, apesar disso, foi referida por apenas 5 enfermeiras, sendo que destas, 3 náo justificaram porque a 
realizam. Esse fato evidencia que as enfermeiras não atribuem importância à passagem de plantão, pois mesmo participando da realização dessa atividade não a referem em, quando a referem, não justificam a sua importancia. Esse fato pode explicar a realidade, muitas vezes, encontrada, quando essa atividade nāo é percebida como troca de informaçōes necessárias para o planejamento da assistência ou como orientaçäo do pessoal de enfermagem, havendo prejuízo, nesses casos, para a qualidade e a continuidade da assistência prestada.

Outra atividade referida, foi a "anotaçāo no prontuário do paciente", que foi citada por apenas uma enfermeira, não tendo esta apresentado justificativa para a sua realizaçäo. Causa estranheza a ocorrência desse fato, uma vez que as enfermeiras referiram um grande número de atividades relacionadas à assistência direta aos pacientes, como pode ser visto na tabela 1 , parecendo evidenciar que as atividades executadas não estão sendo registradas e os prontuários dos pacientes não estāo recebendo a devida atençāo. Como afirma FAVE$\mathrm{RO}^{8}$, é indispensável o uso da comunicação escrita no prontuário do paciente. Vários autores ressaltam a importância do valor legal das anotaçōes e a sua contribuição para o diagnóstico, terapêutica e prognóstico dos pacientes, bem como a sua importância para os programas de saúde e sua utilizaçāo para o ensino, pesquisa e auditoria. Segundo OGUISSO ${ }^{13}$," por disposição legal, o pessoal de enfermagem é obrigado a registrar o resultado de suas observaçōes e toda medicação ou tratamentos administrados, mas, mesmo assim, nāo é, muitas vezes, uma atividade realizada.

Outra atividade referida foi o "acompanhamento de visita médica". Essa atividade nāo parece ser realizada com o intuito de obter mais informações sobre o paciente, mas, sim, como foi referido, com o objetivo de "ter um bom relacionamento com a equipe médica".

Pela fala de algumas enfermeiras, parece haver uma grande preocupaçāo em manter bom relacionamento com a equipe médica, nāo tendo sido percebida essa mesma preocupaçāo em relação à equipe de enfermagem. Um ponto a ser considerado é o fato de que as atividades que são realizadas com a finalidade de manter bom relacionamento com a equipe médica, poderiam ser bastante eficazes se fossem realizadas com o objetivo de melhorar a assistência prestada ao paciente.

\subsection{ATIVIDADES RELACIONADAS A BUROCRACIA CONSTITUÍDA}

Como podemos observar na tabela 5 , as atividades burocráticas foram referidas por 8 enfermeiros, recebendo 14 citações. 
TABELA 5 - DISTRIBUIÇÃO DAS ATIVIDADES BUROCRÁTICAS DESENVOL VIDAS PELAS ENFERMEIRAS, COM AS RESPECTIVAS JUSTIFICATIVAS. SÃO PAULO, 1991

\begin{tabular}{|c|c|c|c|c|c|c|c|c|c|c|c|c|c|c|c|c|c|c|c|c|c|}
\hline Abildedes & 1 & 2 & 3 & 4 & 5 & 6 & 7 & 0 & 9 & 10 & 11 & 12 & 13 & 14 & 15 & 10 & 17 & 18 & 19 & $\begin{array}{l}n \\
\text { do } \\
\text { Ent. }\end{array}$ & $\prod_{n=19}^{x}$ \\
\hline Execuct to de rotinew & & $B E$ & 0 & A & & & & & & & & & & & & 0 & & & & 4 & 21,08 \\
\hline Enboregsto do Cempos & & & & & & & 0 & & & & & & & & & 1 & 0 & & & 3 & 15,78 \\
\hline 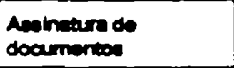 & & & & & & & 0 & & & & & & & & & & & & $D$ & 2 & 10,53 \\
\hline 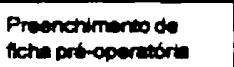 & & & & & & & 0 & & & & & & & $F$ & & & & & & 2 & 10.53 \\
\hline 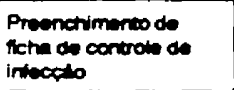 & & & & & & & & & & & & & & & & $\begin{array}{l}G \\
H\end{array}$ & & & & 1 & 5,28 \\
\hline 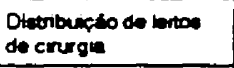 & & & & & & & & & & & & & & c & & & & & & 1 & 5.26 \\
\hline 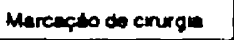 & $A$ & & & & & & & & & & & & & & & & & & & $\therefore$ & 5.28 \\
\hline Burocrescen om gerew & & & & & & & & 0 & & & & & & & & & & & & 1 & 5.28 \\
\hline
\end{tabular}

Legenda:

A - Importante porque beneficia o paciente.

B - Importante porque a enfermeira entra em contato com o paciente.

C - Importante para situar um paciente que necessita de repouso, observação e tratamento cirúrgico.

D - Não justificou.

E - Porque apesar de ser uma atividade de segundo plano, ela faz parte do serviço.

F - Para conhecer as particularidades do paciente, para adequar os cuidados durante o ato operatório.

G - Para detectar foco de infecçảo.

$\mathrm{H}$ - Para proteger o funcionário.

I - Porque é o ponto central de informaçào sobre a presença do paciente.

A atividade mais citada neste grupo foi a execução de rotinas e a elaboraçāo de censo diário de pacientes.

As enfermeiras realizam atividades, denominadas burocráticas, sem salientar a importância das mesmas, uma vez que metade das citações não foram justificadas. Com isso depreende-se que as enfermeiras executam as atividades de forma rotineira, sem refletirem sobre a importância delas na prática.

\subsection{OUTRAS ATIVIDADES}

Nesse grupo foram feitas 10 citaçōes de diferentes atividades que não foram consideradas nos grupos anteriores. 
TABELA 6 - DISTRIBUIÇĀO DE OUTRAS ATIVIDADES DESENVOLVIDAS PELAS ENFERMEIRAS, COM AS RESPECTIVAS JUSTIFICATIVAS. SĀO PAULO, 1991.

\begin{tabular}{|c|c|c|c|c|c|c|c|c|c|c|c|c|c|c|c|c|c|c|c|c|c|}
\hline Entiormairos & 1 & 2 & 3 & 4 & 5 & 6 & 7 & 8 & 9 & 10 & 11 & 12 & 13 & 14 & 15 & 16 & 17 & 18 & 10 & $\begin{array}{l}\text { mo } \\
\text { dent. } \\
\text { End }\end{array}$ & $\begin{array}{l}\infty \\
n \geq 19\end{array}$ \\
\hline 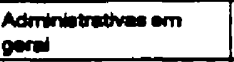 & & & & & $A$ & & & & & & & B & & & & & & & & 2 & $10.53 \mid$ \\
\hline $\begin{array}{l}\text { Orgentractor da } \\
\text { uridede }\end{array}$ & $A$ & & & & & & & & & & 10 & & & & & & & & & 2 & 10,53 \\
\hline 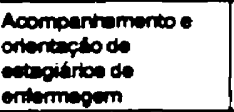 & & & & & & & & & & & & B & & & & c & & & & 2 & 10,53 \\
\hline 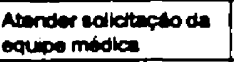 & & & & & & & & & & & & & & & & & & & $E$ & 1 & 5.28 \\
\hline $\begin{array}{l}\text { Levantarmento os } \\
\text { problemente }\end{array}$ & & & & & & & & & & & & & & & & c & & & & 1 & 5.26 \\
\hline $\begin{array}{l}\text { Remoluctio de } \\
\text { prodereme: }\end{array}$ & & & & & & & & & & C & & & & & & & & & & & 5.26 \\
\hline
\end{tabular}

\section{Legenda:}

A - Importante porque beneficia o paciente.

B - Importante.

C - Nāo justifícou.

D - Porque sem organizaçāo não dá para trabalhar.

E - Para ter um bom relacionamento com os médicos.

Dentre essas citaçōes, salienta-se a de uma enfermeira que referiu desenvolver atividades voltadas para o ensino de estagiários de enfermagem. É de se estranhar a pouca ocorrência desse fato, pois os dados desse trabalho foram levantados com enfermeiras de um hospital de ensino, nas unidades onde os alunos de graduação esta vam estagiando.

\section{CONCLUSĀO}

Devido a diversificação das atividades citadas pelas enfermeiras, bem como pelas justificativas mencionadas, pode-se concluir que essas profissionais realizam atividades por decisāo pessoal e nāo por se considerarem elementos integrantes de um grupo, ao qual compete um elenco de atividades estabelecidas, por consenso, pelo grupo de enfermeiros da orga nização em estudo. Is to parece evidenciar que, não existindo o consenso, há dificuldade desse grupo em estabelecer objetivos e uma política assistencial de enfermagem, o que gera dificuldades na definiçăo das atividades a serem desenvolvidas pelos enfermeiros, bem como na percepçāo da importáncia delas para o alcance desses objetivos. 
Essa diversificação de atividades e justificativas permite concluir, ta mbém, que as atividades são realizadas de forma desvinculada dos processos de planejamento e tomada de decisão.

A análise da percepçāo das enfermeiras referentes às atividades que realizam, mostra que a importância atribuída a essas atividades, muitas vezes, não são citadas ou, então, as enfermeiras não justifícam a sua execução. A falta de justificativa leva a crer que o significado das atividades desenvolvidas não é percebido claramente pelas enfermeiras, fazendo com que embasem sua prática na rotina, na tradição e na autoridade.

Dessa forma, não é a reflexáo da prática que direciona a realização das atividades, tornando-a reiterativa.

A não reflexão sobre a prática, também é percebida, quando se verifica que as atividades relacionadas à pesquisa não foram citadas uma única vez. A não realização de pesquisas compromete o "saber" da enfermagem, tão importante para o seu desenvolvimento, enquanto profissão, e para o reconhecimento social do trabalho do enfermeiro.

KURCGANT, $P$. et al. Nursing perceptions about acitivities that realize in their nurses units. Rev. Esc. Enf. USP., v. 27, n² 2, p. 229-45, aug. 1993.

The goal of this study is to verify the activities of unit nurses and anbulatory nurses in governamental hospital and to know they perceive these activities. The populacion was composed by 19 nurses of both unites. The data was collect using structured interviews, and analysed in quantitative and qualitative dimensions. The results demostrated that nurses work as routine activities, based in tradicition and cuthority and there was no reflection about practice, causing a reiterativa practice.

UNITERMS: Nursing as a profession. Nursing services.

\section{REFERÊNCIAS BIBLIOGRÁFICAS}

1. BRASIL.Leis, etc. Decreto $n^{\vee} 94.406$ de 8 de junho 1987. Regulamenta a Lei $n^{2} 7.498$ de junho de 1986 que dispóe sobre o exercício da enfermagem e dá outras providèncias. Diário Oficial da Uniào, Brasilia, 9 jun. 1987. p.8.853-5.

2.

Lei $n^{2} 7.498$ de 25 junho 1986 . Dispóe sobre a regulamentaçáo do exercicio da enfermagem e dá outras providèncias. Diário Oficial da Uniāo, Brasilia, 26 jun. 1986. p.9.273-5.

3. Ministério da Saúde.Guia de supervisão em estabelecimentos de saude. Brasilia, Centro de Documentação, 1981.

4. CAPELLA, B.B. et al. Profissionalizaçajo da enfermagem: uma necessidade social. Rev.Bras.Enf., v.41, n.2, p.161.8, 1988.

5. CASTELLANOS, B.E.P.: CASTILHO, V. Marco conceitual da assistència de enfermagem: consideraçóes gerais. IN: CAMPEDELLI, M.C. et al. Processo de enfermagem na prática. Sảo Paulo, Atica, 1989. p.22-30. 
6. CUNHA, K. de C. Filosofia do serviço de enfermagem. IN: KURCGANT, P. Administragão em enfermagem. São Paulo, EPU, 1991. cap.2, p.15-21.

7. Superviøão em enfermagem. IN: KURCGANT, P. Administração em enfermagem. São Paulo, EPU, 1991, cap.10, p.117-32.

8. FAVERO, N. et al. A importáncia da comunicaçáo como um instrumento administrativo: eopecial referência à anotaçăo de enfermagem. Rev.Paul.Hosp., v.31, n.1/2, p.4-7, 1983.

9. HERSEY, P.; BLANCHARD, K.H. Paicologia para adminiotradores a teoria e as técnicas da liderança situacional. Sáo Paulo, EPU, 1986.

10. KAST, F.E.; ROSENZWEIG, J.E. Organização e administração: um enfoque oistêmico. 2.ed. São Paulo, Pioneira, 1980.

11. LAMBERTSEN, E.C. Equipe de enfermagem: organizaçăo e funcionamento, ABEN, 1966.

12. MELO, C. Divisào social do trabalho e enfermagem. Sāo Paulo, Cortez, 1986.

13. OGUISSO, T. Os aspectos legais da anotaçāo de enfermagem no prontuário do peciente. São Paulo, 1975. 116p. Tese (Livre-docéncia)-Escola de Enfermagem Ana Neri, Universidade Federal do Rio de Janeiro. 


\section{ANEXO}

\section{ESCOLA DE ENFERMAGEM DA UNIVERSIDADE DE SĀO PAULO}

ADMINISTRAÇĀO APLICADA A ENFERMAGEM

\section{ENTREVISTA}

1. Que atividades vocé desenvolve na sua unidade?

2. Que importância você dá a cada uma dessas atividades? 